\title{
Correction to: Martensitic microstructure evolution in austenitic steel: $A$ thermomechanical polycrystalline phase field study
}

\author{
Bhasker Paliwal, ${ }^{1,2, a)}$, Robert D. Moser ${ }^{3}$, Christopher D. Barrett ${ }^{1,2}$, Willburn R. Whittington ${ }^{1,2}$, \\ Hongjoo Rhee ${ }^{1,2}$, YubRaj Paudel ${ }^{2}$, Shiraz Mujahid ${ }^{2}$, Haitham El Kadiri ${ }^{1,2,4}$ \\ ${ }^{1}$ Department of Mechanical Engineering, Mississippi State University, 479-1 Hardy Road, Mississippi State, MS 39762, USA \\ ${ }^{2}$ Center for Advanced Vehicular Systems, Mississippi State University, 200 Research Boulevard, Starkville, MS 39759, USA \\ ${ }^{3}$ Engineer Research and Development Center, U.S. Army Corps of Engineers, 3909 Halls Ferry Road, Vicksburg, MS 39180-6199, USA \\ ${ }^{4}$ Université Internationale de Rabat Technopolis, Rabat-Shore Rocade Rabat-Salé, 11103 Rabat, Morocco \\ a) Address all correspondence to this author. e-mail: paliwb@rpi.edu
}

Published online: 11 June 2021

\section{Correction to:}

Journal of Materials Research

https://doi.org/10.1557/s43578-021-00209-2

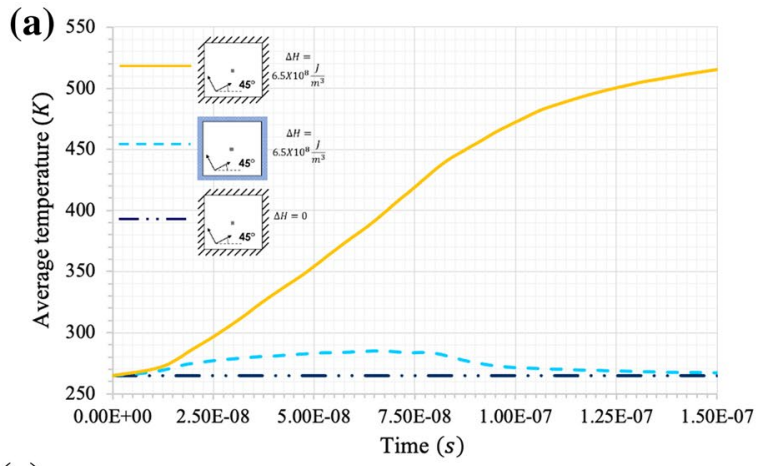

(c)

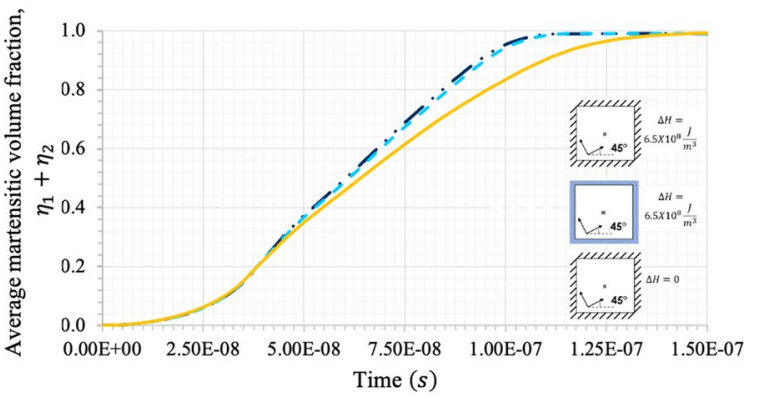

Figure $7 \mathrm{~b}$ is incorrect in the original publication of this article. Figure 7 appears correctly here.

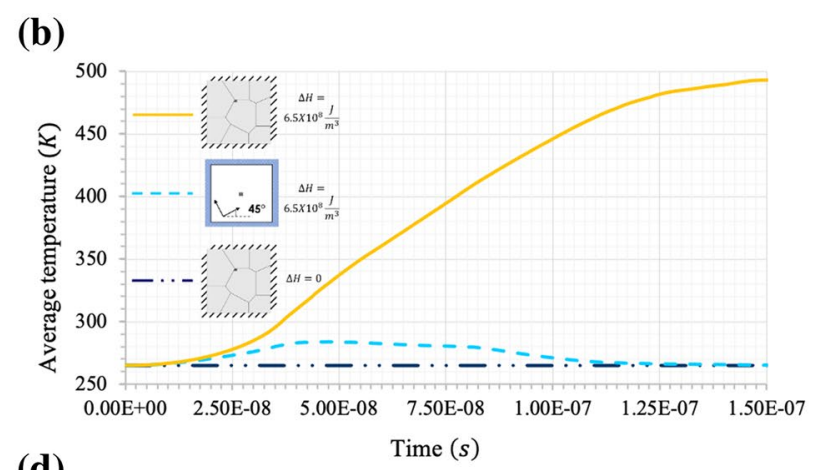

(d)

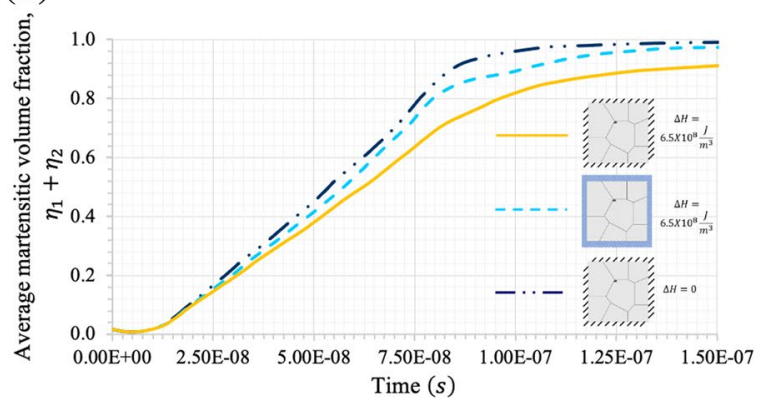

Figure 7: Plots showing evolution of average temperature in austenitic (a) single crystal and (b) polycrystal subjected to thermal boundary conditions corresponding to adiabatic, isothermal, and adiabatic without the latent heat. Near-open mechanical boundary condition is applied. Plots showing evolution of average martensitic volume fraction in austenitic (c) single crystal and (d) polycrystal, subjected to thermal boundary conditions corresponding to adiabatic, isothermal, and adiabatic without the latent heat. Near-open mechanical boundary condition is applied.

The original article can be found online at https://doi.org/10.

1557/s43578-021-00209-2 